\title{
Teaching Medical Students in Primary and Secondary Care: a Resource Book (Sarah Hartley, Deborah Gill, Frances Cater)
}

- Title: Teaching Medical Students in Primary and Secondary Care: a Resource Book

- Author: Sarah Hartley, Deborah Gill, Frances Cater

(양은배, 이승희, 황은영 공역)

- Publisher: Oxford University Press

의학교육에 대한 의과대학/의전원의 관심들이 크게 높아지고 있다. 원래 의과대학이나 의전원이 학생들에게 의학교육을 시키는 곳인데, 새삼스레 무슨 말이냐고 질 문하실지 모른다. 그러나 사실, 그렇지 않았었다는 것을 우리 모두는 알고 있다. 의과대학/의전원에서는 교수들 이 연구와 임상에 거의 모든 시간을 쓰고 있고, 따라서 교육은 항상 가장 가벼운 부속물로 처리되어 왔다. 그러 나 의과대학 인증평가 제도가 시행되기 시작하였고, 의 학도들이 가지는 국제적 경쟁력에 대한 강조가 이루어지 기 시작하면서, 의학교육은 이제 의과대학/의전원의 중 요 관심사항이 되어가고 있는 것이다.

그런데 문제는 자신의 전공 분야에 대한 공부와 연구만 으로도 매우 바쁜 의대교수님들이 의학교육에 대한 관심 을 가지고 최신 개념을 쉽고도 명확히 이해하기에 좋은 책들이 많지 않다는 것이다. 의대교수들을 위한 “의학식 간단명료성"을 잘 갖춘 책은 그래서 매우 중요한 의미를 가진다. 특히 교육 현장에서 사용되어져야 하는 좋은 의 학교육 방법론에 대한 관심을 가지고 계신 분들께 적합 한 책을 찾고 있다면, 이제 한국의학교육학회에서 우수 저서번역상을 수상한 좋은 번역서가 한 권 나왔음을 알 려드려야 할 것 같다.

이 책은 지식의 전달이 의학교육현장에서 제대로 이루 어지게 하기위해 의학교육 교수학습 방법론에 대해 다루 고 있으며, 교육학 이론과 의학교육 상황을 잘 조화시켜 설명하고 있다. 또한 의과대학 교수들이 학생 교육에 직

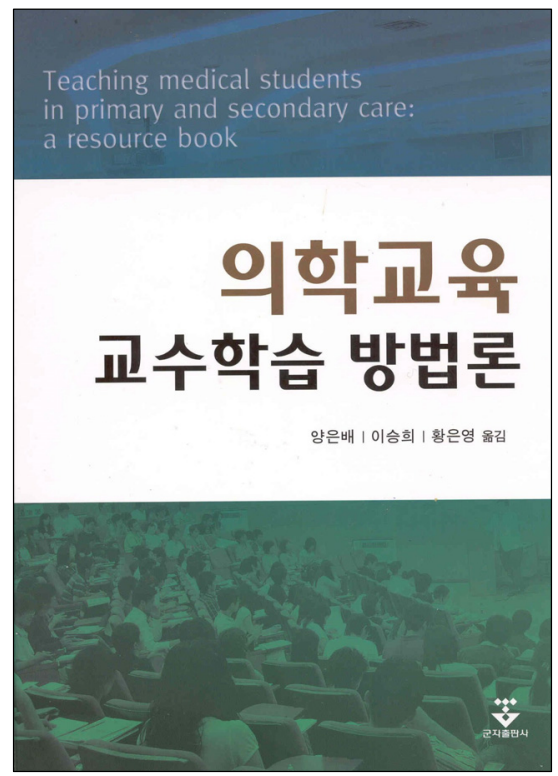

접 적용할 수 있는 실용 지침서로써 활용될 수 있다. 이 책은 크게 12 개의 장으로 구성되어 있다. 각각의 구성 내 용은 교수학습의 일반적인 원칙, 수업준비, 효과적인 수 업을 위한 다양한 기술을 소개하고 있으며, 교육 주제별, 대상별, 장소별 교수방법에 대해 다루었다. 또한 후반부 에서는 교육과정 설계와 평가, 교수개발에 대해서도 기

\footnotetext{
Korean J Med Educ 2009 Mar; 21(1): 79-80.

doi: 10.3946/kjme.2009.21.1.79.

(C) The Korean Society of Medical Education. All rights reserved.
} 
술함으로써 의학교육의 교육방법론의 중요성을 강조하 고 있다. 이 책은 교육관련 자료뿐만 아니라 임상교수들 이 교육에 대한 확신과 유연성을 가질 수 있도록 실제적 인 정보들을 포함하고 있으며, 교육관련 연구를 진행할 때도 좋은 참고서가 된다. 흥미롭게도 독자들이 능동적 으로 학습할 수 있도록 상호작용적인 양식을 채택하고 있다. 교육은 잘 개발된 문서가 아니라 강의실과 임상실 습 병원에서의 학생 경험이며, 의과대학의 교수들은 이 러한 경험의 핵심에 있다. 이 책은 의과대학 학생과 전공
의 교육에 남다른 관심과 열정을 갖고 있는 의과대학 교 수들을 위한 책이다. 이 책을 책상 한 모퉁이에 두고, 필 요할 때는 언제든지 참고할 수 있고 사용할 수 있게 되시 기를 적극 권해 드린다.

전우택, 연세의대 정신과/의학교육학과 Woo Taek Jeon, Department of Psychiatry/Education, College of Medicine, Yonsei University, Seoul, Korea 